\title{
DEVELOPMENT OF AN INTEGRATED DISCOUNTING STRATEGY BASED ON VENDORS' EXPECTATIONS USING FAHP AND FUZZY GOAL PROGRAMMING
}

\author{
Irem UCAL SARI \\ Industrial Engineering Department, Management Faculty, Istanbul Technical University, \\ ITU Macka Kampusu, 34367, Istanbul, Turkey
}

Received 29 September 2015; accepted 11 June 2016

\begin{abstract}
The main goal of a company is to increase its market share and total profits at the same time. However, these two objectives conflict if discount rates are applied to vendors. The objective of this paper is to develop an integrated discounting strategy method to effectively manage the transactions of the vendors by determining the optimum discount rates which balance the increase on the market share and the total profit. With the proposed methodology which utilizes fuzzy analytic hierarchy process and fuzzy goal programming, determination of the discount rates of each vendor under different discounting strategies is facilitated. This enables the vendors to choose the most suitable discounting strategy with the best applicable discount rate and enables the managers to predict the transactions of the vendors. The proposed method is validated with a numerical study conducted on a pilot region of an international company.
\end{abstract}

Keywords: discounting strategy, fuzzy goal programming, fuzzy analytic hierarchy process, revenue management, risk management, supply chain management.

JEL Classification: G610, L60.

\section{Introduction}

The convenience introduced by telecommunication and transportation systems among long distances has increased the number of international companies in a significant way in all industries. International companies usually have larger networks which makes it difficult to manage all the activities in a supply chain. In supply chain management, vendors have an important role for the company, which determines the level of attainability of the company to the end user. Due to the fact that the successes of vendors directly affect the sales volume

Corresponding author Irem Ucal Sari

E-mail: ucal@itu.edu.tr 
and the market share, vendors have significant importance in supply chains, especially for B2B companies.

In supply chain management, there are several crucial vendor management activities. In literature, it is seen that the studies on the management of vendors are mainly focused on vendor performance measurement and vendor selection problems. Weber et al. (1991) and Aissaoui et al. (2007) examined and classified previous papers related to vendor selection process and provided a detailed literature review of the papers on vendor selection problems. It is observed that Analytic Hierarchy Process (AHP) is used widely in vendor selection problems (Tam, Tummala 2001; Yahya, Kingsman 1999; Yang et al. 2008). However, the conventional AHP can only deal with definite scales in reality and cannot involve massive uncertainties and subjectivities (Zeng et al. 2007). Therefore, Van Laarhoven and Pedrycz (1983) developed fuzzy AHP (FAHP) to solve the hierarchical fuzzy problems. There are several papers that used FAHP in vendor and supplier selection problems (Haq, Kannan 2006; Kahraman et al. 2003; Ertuğrul, Karakasoglu 2009; Shaw et al. 2012; Galankashi et al. 2015; Kilincci, Onal 2011; Jakhar 2015; Kar 2014). Goal programming is also used to define the most valuable vendors in various papers (Kumar et al. 2004; Wadhwa, Ravindran 2007; Kar 2014; Senvar et al. 2014).

For companies with numerous vendors, it is important to take the strategies and goals of their vendors into account to set achievable future plans and goals. The main goal of a company is to have maximum total profit obtained through the sales of its products or services. In the simplest manner, profit can be defined as the difference between the total earnings and the total costs. To increase the total profit, companies can either decrease their costs or increase their unit profit. If the costs are constant, which means that all possible improvements have been made to decrease costs, the main purpose of the company becomes to increase their unit profit. It would be easier if the unit sales price of a product does not affect the demand of the customers but in reality vendors are quite price sensitive. That's due to the fact that the main goal of the vendor is the same as the main company, to have the highest profit. As the list prices are determined by the company according and relative to the market, competitors and the customer segments; the vendors want to get the highest discount in order to attain the largest profit. Higher discount rates will lead the vendor to order larger amounts considering economies of scale. To achieve its ultimate goal, companies may prefer different strategies. Some companies may prefer to gain through demand which means they sell their goods at relatively lower prices that increases the total sales amount and therefore, total profit. The others may prefer to have relatively higher unit profits and keep the sales amount at a certain level which is relatively low. But most of them intend to find the balance between these two strategies. In order to maximize the total profit, a company should well-determine the discount rates aiming to obtain a balance between the losses due to the discounts and the earnings through the increased demand. Determination of this balance point is a multi-objective problem which is not easy to solve without a complex programming model.

In literature, there are a lot of articles that deal with the quantity and volume discounts of suppliers and vendors; and most of them have studied the problems from the perspective of the vendors. Wang and Yang (2009) proposed a Fuzzy Compromise Programming model to take the quantity discount rates of the suppliers into account for the selection process. Viswanathan 
and Wang (2003) evaluated the effectiveness of alternative discount schemes in a simplified setting of a single-vendor, single-retailer and distribution channel. They developed methods that determine the optimal volume discount, quantity discount, and combined quantity and volume discount policies. Kamali et al. (2011) proposed a multi-objective integrated inventory model in which joint optimization and quantity discount schemes are used to develop coordination between the two parts of the supply chain that enhances the overall performance of the system. Some articles which deal with the quantity and volume discounts of suppliers and vendors have studied the discounting problem from the supplier perspective. Sinha and Sarmah (2010a) developed a single vendor, multi-buyer supply chain coordination model through proposing an optimal discount pricing policy. The model groups all the buyers into different discrete clusters and determines the discount schedule for each cluster using an evolutionary search technique. However, real-world applications of this model are quite limited as it only considers the deterministic demand for any buyer which is a highly unrealistic and restrictive assumption in terms of practical applicability. Sinha and Sarmah (2010b) extended this model under stochastic demand environment. Braide et al. (2012) developed a method to construct a volume discount price scheme and showed that any volume discount can be represented as a piecewise function of demand. Yin and Kim (2012) proposed a method to optimize container lines' freight tariffs in order to maximize their expected profit by considering changes in order quantities made by forwarders' responding to the price schemes suggested by the container lines. They designed an analytic model that addresses all-unit quantity discount schemes with single or multiple price-break points. Kumar (2016) proposed a fuzzy model which captures the dynamic variations in sales of a product based upon the dynamic estimation of the time series data to determine the dynamic price discounting strategy. Chung and $\mathrm{Li}$ (2013) analyzed the data collected from perishable food industries to find out the impact of a multi-period dynamic pricing strategy on consumers. The findings suggest that food retailers can enhance customer satisfaction by offering an earlier but lower discount, and increasing it as perishable food items approach their expiry date, rather than a higher discount when the expiry date is imminent. Croes et al. (2010) provided a theoretical framework that investigates the fundamentals of discounting, and empirically assesses the efficacy of the discounting process in the lodging industry. In this study the dynamics of the cyclical behavior of the lodging industry are recognized as integral variables in the discounting strategy process by applying the rational expectations theory. Harries et al. (2004) examined the influence of outlying opinions within a learning paradigm with feedback in their study which shows that it is easy to reinforce a discounting strategy (with feedback) whereas it is more difficult to counteract this default strategy. Wang and $\mathrm{Hu}$ (2014) investigated the effect of committed fixed pricing strategy and contingent pricing strategy for the fixed capacities under demand uncertainty. Cheng (2013) discussed dynamic price discounts integrated with rationing policy for two demand classes in a deterministic environment. Hsieh et al. (2010) considered a short-term discounting model in which the distributor offers a discounted price for the price sensitive retailers' orders placed at the beginning of its replenishment cycle.

The literature clearly states that there is a need to a holistic approach for discounting strategy management for companies which includes different discounting policies and discounting rates for each vendor based on their performances and expectations. 
Most of the real word problems including discounting strategy problems have multiple criteria and multiple objectives. Multi criteria decision making (MCDM) is a useful tool for suggesting solutions for problems under the presence of a number of decision criteria. There are lots of methods used for solving MCDM problems in the literature. Fuzzy analytic hierarchy process (FAHP) which enables the analyst to convert linguistic definitions into mathematical expressions is one of the most used MCDM methods due to its practical application. Multiple objective decision making (MODM) problems mostly do not have a solution which optimizes all of the related objective functions. Fuzzy goal programming is one the most used methods to solve MODM problems. The algorithm focuses on the prioritization of different goals (even if they are conflicting) and searches for the best solution which minimizes the deviations from the targets determined for objective functions of each goal.

The aim of this paper is to develop an integrated discounting strategy method for companies to increase their total profit and market share together. The method searches for the best discounting strategy and the best discounting rate for each vendor to balance the conflicting goals of the companies. In this proposed method, vendors are categorized according to their risk levels by using expert opinions and past data. According to the determined risk levels, the acceptable discounting rate intervals are assigned. Then, a fuzzy goal programming model is used to find out the optimum discount rates for different discounting strategies in an acceptable range for each vendor which will maximize the total profit and total sales amount.

To the best of our knowledge this paper is the first study on determination of the best discounting strategy which takes into account both manufacturer's and vendor's expectations. It integrates the past experiences of the manufacturers by using the risk levels of the vendors and the effects of the determined discounting strategy on the sales performances of the vendors to increase both total profit and market share of the manufacturers.

The rest of the article is organized as follows. In Section 1, the methodology of the proposed model is given including basic concepts of the methods used in the model. A real world application of the proposed model is provided in Section 2. The article is concluded with discussions of the results and recommendations on future researches.

\section{Methodology}

Determining discount rates for vendors involves several analyses such as defining the preferred discount strategies, categorization of the vendors according to their importances' and risk levels, determination of their potential sales volume at different discount rates and optimizing the net revenue. The proposed method consists of seven steps that are detailed as given below:

\subsection{Determination of the discounting strategies}

In the first step of the proposed method, the preferred discounting strategies for each vendor are determined by using questionnaires. It is important to extract the information of the relationship between the preferred discounting strategy and the percentage of the discount rate. The vendors are asked to define at what improvement on discount rates for their second preferred discounting strategy makes it their first choice. In this model, the following four strategies are used, which absolutely can be changed through the preferences of the companies. 
DS1: The discount rate is fixed at the beginning of the year for an agreed total yearly sales volume. In this strategy, a commitment is made at the very beginning of the year with the vendor who prefers this strategy. In this commitment, the total yearly purchasing amount for the vendor is determined together with a specific discount rate for that amount that is agreed upon. This discount rate remains the same for all orders independent from the ordering amount. This strategy enables the managers to forecast the demand of the products exactly.

DS2: The discount rate is determined by the ordering amount and is different for each order. In this strategy, the intervals of the purchasing amounts for each vendor which will have different discount rates are determined first. For each order of the vendor, the discount rate of the interval which the ordering amount belongs to is used. In this strategy, the performance or the potential of the vendor does not affect the discount rate. This strategy encourages the vendors to order greater amounts which can be a greater benefit for the managers if the shipment costs are paid by the company.

DS3: The discount rate is determined for each order depending on the total previous order amount of the vendor. In this strategy, the total quantity levels for each vendor are determined. In each order, total previous order amount is revisited and when the cumulative previous order amounts of a vendor sum up to a value greater than a certain predetermined quantity level, the discount rate is changed. In this strategy, profit ratio is higher in the first orders, enabling the company to be on the safe side in case the total quantity goals are not met.

DS4: The discount rate is fixed at the beginning of the year and additional discounts over the total sales will be paid as a bonus to the vendor at the end of the year depending on the different levels of total yearly sales volumes. In this strategy, total order quantity intervals which will have different unit bonuses are determined by the experts and the unit bonus of the related interval for the total ordering quantity of a vendor at the end of the year is paid back to the vendor. This strategy enables the managers to utilize and invest the money which will be paid to the vendor for its success in another investment opportunity within the related year.

\subsection{Determination of the vendor expectations and behaviours}

In this phase, the questionnaire which is used to determine the preferred discount strategy for each vendor is prepared. In this questionnaire, 4 discounting strategies which are detailed in Section 1.1 are asked to be prioritized by vendors. In the last part of the questionnaire, vendors decide on their expected improvement ratios on their total sales volume when they get $1 \%, 2 \%$ and $3 \%$ additional discounting. The results of the last question are compared to the past data and used in Section 1.6 if the past data does not provide any meaningful relations between the discount rate and the sales volume (especially when the discount rate of a vendor has been same for all the past orders).

\subsection{Determination of the criteria for risk levels of vendors}

In this step, experts and managers define the criteria which directly affect the risk of a vendor. In this model, three criteria and their sub-criteria that affect the risk level of a vendor, which may vary from company to company, are defined as follows. The first criterion is the financial yield $(F Y)$ which represents the financial effects of the vendor to the company. There are two 
sub-criteria of financial yield which are sales revenue (SR) and profitability $(\mathrm{Pr})$. SR refers to the total income of the vendor whereas $\operatorname{Pr}$ refers to the total profits gained from that vendor. Second criterion is the strategic worth $(S W)$ of the vendor which has three sub-criteria. The first sub-criterion of SW is product diversity $(P D)$ which has higher values if the number of product types purchased by the vendor is high. Ordering number $(\mathrm{ON})$ is another sub-criterion of $S W$ which refers to the frequency of the orders. Potential $(\mathrm{Po})$ is the last sub-criterion of $S W$ which refers to the purchasing potential of the vendor in the future. Financial note (FN) is the last criterion which has two sub-criteria. Financial risk $(F R)$ is the first sub-criterion of $F N$ which is the payment ability of the vendor determined by liquidity, trade register and equity capital of the vendor. Regular payment $(R P)$ is another sub-criterion of $F N$ which shows delays of the payments.

\subsection{Determination of the criteria weights for risk levels of vendors}

Fuzzy Analytic Hierarchy Processing method is used to weight the effects of the criteria and sub-criteria for determining the risk level of a vendor. In literature, there are many FAHP methods proposed by various authors. In this study, we apply Buckley's (1985) geometric mean method to calculate fuzzy weights and performance which guarantees a unique solution to the reciprocal comparison matrix with the linguistic variables given in Table 1.

Table 1. Definition and the scale of the linguistic variables

\begin{tabular}{|c|c|c|}
\hline $\begin{array}{l}\text { Fuzzy } \\
\text { number }\end{array}$ & Linguistic variable & $\begin{array}{c}\text { Scale of fuzzy } \\
\text { number }\end{array}$ \\
\hline$\tilde{1}$ & Equally important (EI) & $(1,1,3)$ \\
\hline$\tilde{3}$ & Weekly more important (WI) & $(1,3,5)$ \\
\hline$\tilde{5}$ & Moderately more important (MI) & $(3,5,7)$ \\
\hline$\tilde{7}$ & Greatly more important (GI) & $(5,7,9)$ \\
\hline$\tilde{9}$ & Absolutely more important (AI) & $(7,9,9)$ \\
\hline$\frac{1}{\tilde{A}}$ & $\begin{array}{l}\text { If factor } i \text { has one of the above fuzzy numbers assigned to it when compared } \\
\text { with factor } j \text {, then } \mathrm{j} \text { has the reciprocal value when compared with } i \text {. }\end{array}$ & $\begin{array}{l}\text { Reciprocals } \\
\text { of above }\end{array}$ \\
\hline
\end{tabular}

The procedure of FAHP for determining the evaluation weights are explained as follows:

Step 1. Construct the pairwise comparison matrices

Each element $\left(\tilde{a}_{i j}\right)$ of the pairwise comparison matrix $\tilde{A}$ is a linguistic terms presenting which is the more important of two criteria. The pairwise comparison matrix is given by:

$$
\tilde{A}=\left[\begin{array}{cccc}
1 & \tilde{a}_{12} & \cdots & \tilde{a}_{1 n} \\
\tilde{a}_{21} & 1 & \cdots & \tilde{a}_{2 n} \\
\vdots & \vdots & \ddots & \vdots \\
\tilde{a}_{n 1} & \tilde{a}_{n 2} & \cdots & 1
\end{array}\right]=\left[\begin{array}{cccc}
1 & \tilde{a}_{12} & \cdots & \tilde{a}_{1 n} \\
1 / \tilde{a}_{12} & 1 & \cdots & \tilde{a}_{2 n} \\
\vdots & \vdots & \ddots & \vdots \\
1 / \tilde{a}_{1 n} & 1 / \tilde{a}_{2 n} & \cdots & 1
\end{array}\right] .
$$


Step 2. Examine the consistency of the fuzzy pairwise comparison matrices

Assume $A=\left[a_{i j}\right]$ is a positive reciprocal matrix and $\tilde{A}=\left[\tilde{a}_{i j}\right]$ is a fuzzy positive reciprocal matrix. If the result of the comparisons of $A=\left[a_{i j}\right]$ is consistent, then it implies that the result of the comparisons of $\tilde{A}=\left[\tilde{a}_{i j}\right]$ is also consistent (Buckley 1985). In order to check the consistency of the fuzzy pairwise comparison matrices, pairwise comparisons are defuzzified by the graded mean integration approach. According to the graded mean integration approach, a triangular fuzzy number $(T F N) \tilde{A}=(l, m, u)$ can be transformed into a crisp number by employing the below equation:

$$
A=\frac{l+4 m+u}{6} .
$$

Step 3. Compute the fuzzy geometric mean for each criterion

If $\left(\tilde{r}_{i}\right)$ is geometric mean of each row of $\tilde{A}=\left[\tilde{a}_{i j}\right]$ then it is calculated as below:

$$
\tilde{r}_{i}=\left[\tilde{a}_{i 1} \otimes \ldots \otimes \tilde{a}_{i n}\right]^{1 / n} \text {. }
$$

Step 4. Compute the fuzzy weights by normalization

If $\left(\tilde{w}_{i}\right)$ is the fuzzy weight of the $i^{\text {th }}$ criterion, which is represented bya TFN, $\tilde{w}_{i}=\left(l w_{i}, m w_{i}, u w_{i}\right)$. Here, $l$ and $u$ are the lower and upper bounds of the fuzzy weight $\tilde{w}_{i}, m$ is the modal value of $\tilde{w}_{i}$. The fuzzy weight of the $i^{\text {th }}$ criterion is calculated as below:

$$
\tilde{w}_{i}=\tilde{r}_{i}\left[\tilde{r}_{1} \oplus \ldots \oplus \tilde{r}_{i} \ldots \oplus \tilde{r}_{n}\right]^{-1} .
$$

Step 5. Defuzzification of fuzzy numbers in order to determine the importance ranking of the criteria In previous works, the procedure of defuzzification has been to locate the best non-fuzzy performance (BNP) value (Hsieh et al. 2004). The Center of Area (COA) method can be used for defuzzification in this step. The $C O A$ method's $B N P$ value for triangular fuzzy number $\tilde{A}=(l, m, u)$ can be calculated as follows:

$$
B N P=\frac{(u-l)+(m-l)}{3}+l, \quad \forall i .
$$

\subsection{Calculation of risk levels for each vendor}

Using the results of Fuzzy Analytic Hierarchy Process method a risk level is determined by Eq. (6) which is given below:

$$
R L=w_{S R} C_{S R}+w_{P r} C_{P r}+w_{P D} C_{P D}+w_{O N} C_{O N}+w_{P o} C_{P o}+w_{F R} C_{F R}+w_{R P} C_{R P},
$$

where $w_{j}$ is the weight of the sub-criteria $j$ and $C_{j}$ is the score of the vendor with respect to the sub-criteria $\mathrm{j}$ that has a value between $[0,10]$. The smaller values of $R L$ mean that the vendor has a greater risk.

In this step it is highly recommended to analyze the vendors by cluster analyses. The results are interpreted by the managers to define which strategies are applicable for each cluster. For example if there is a risk group which is focused on the attribute of payment period, then a discounting strategy which enables vendors pay the bills 120 days later than the shipping, could not be applicable for this group. 
In an easier way, applicable discounting strategy for a vendor could be defined by its risk level. For example, $D S 1, D S 2, D S 3$ and $D S 4$ could be applicable to the vendors which have risk levels greater than $5,3,3,2$, respectively. DS1 is the riskiest discounting strategy, because it gives the best discounting rate to the vendor and if the vendor does not keep his/ her promises the loss of the company will be more than the other strategies. So DS1 should not be applicable for the vendors who have a risk level smaller than a certain value. DS4 is the safest discounting strategy therefore it is applicable for all of the vendors even if they have small risk levels. If the vendor could not reach its target sales amount the manufacturer will not lose profit because of the determined discounting strategy. Between DS2 and DS3, it is possible to say that DS2 is riskier than DS3 because it does not consider past experiences. Thus, among DS2 and DS3, DS3 should be applicable for the vendors who have smaller risk levels whereas DS2 should be applicable for the vendors who have relatively higher risk levels.

\subsection{Determination of the possible effect of the change in the discount rates on sales}

In this step, the past data of each vendor is examined and the increase on the ordering amount by a particular decrease on discounting rate is determined by a function which is symbolized as $S_{i}=f\left(x_{i}\right)$. If the past data does not give any meaningful relation between these two parameters, the results of the questionnaire which is made in Section 1.2 can be used to determine the function.

\subsection{Determination of the fuzzy goal programming model}

In this step, the goals of the company are determined by the managers. There are two conflicting objective functions related to the discounting rates which are:

- Maximizing total sales volume by increasing discount rate,

- Maximizing total profit by decreasing discount rate.

The decision variable of the fuzzy goal programming model is determined as $x_{i}$ which is the discount rate of vendor $i$. In this paper, $l_{p}$ denotes the list price of a unit, $Q_{i \max }$ denotes the yearly amount of maximum order capacity of vendor $i, u_{c}$ denotes the unit cost, $x_{\min }$ denotes the minimum acceptable discount rate, $R L_{i}$ denotes the risk level of vendor $i, \alpha$ denotes the allowable exceed with respect to the competitors price, $C P$ denotes the competitor's price, $Q_{i T t}$ denotes the total sales volume in the year $t$ of vendor $i, E P_{i T}$ denotes the expected total profit of vendor $i$, $E P_{T}$ denotes the expected total profit of company, $S_{i}$ denotes the increase on the sales volume for an additional 0.01 increase on discount rate and $p_{\min }$ denotes the minimum expected unit profit.

\subsubsection{Constructing a mathematical model for DS1}

First of all, two conflicting objectives are formulated. The formulation of profit maximization objective is given in Eq. (7) and the formulation of sales amount maximization objective is given in Eq. (8) as follows:

$$
\begin{gathered}
\max \sum_{i=1}^{n}\left(\left(1-x_{i}\right) l_{p}-u_{c}\right) Q_{i T t} \\
\max \sum_{i=1}^{n} Q_{i T t} .
\end{gathered}
$$


The equations and constraints used in the model can be constructed as follows. Total sales amount is represented in Eq. (9):

$$
Q_{i T(t-1)} \times\left(1+S_{i}\right)^{\left(\frac{\left(x_{i t}-x_{i(t-1)}\right)}{0.01}\right)}=Q_{i T t} .
$$

Allowable discount rates due to the risk levels of each vendor are represented in Eq. (10):

$$
x_{i} \leq \frac{R L_{i}}{10} .
$$

Minimum acceptable unit profit constraint is represented in Eq. (11):

$$
\left(1-x_{i}\right) l_{p}-u_{c} \geq p_{\min } u_{c} .
$$

Minimum discount rate constraint is represented by Eq. (12):

$$
x_{i} \geq x_{\min } .
$$

Maximum sales price constraint in that region w.r.t. the sales price of the closest competitor is represented in Eq. (13):

$$
l_{p}\left(1-x_{i}\right) \leq(1+\alpha) C P .
$$

Maximum ordering capacity constraint is represented in Eq. (14):

$$
Q_{i T t} \leq Q_{i \max } .
$$

Fuzzy goal programming of the DS1 is constructed as follows by using Hannan's approach (1981):

$$
\begin{aligned}
& \max \lambda \\
& x_{i} \geq 1-\frac{(1+\alpha) C_{p}}{l_{p}} \\
& x_{i} \leq 0.1 R L_{i} \\
& x_{i} \leq 1-\frac{p_{\min } u_{c}+u_{c}}{l_{p}} \\
& Q_{i T t}=Q_{i T(t-1)} \times\left(1+S_{i}\right) \\
& \sum_{i=1}^{n}\left(\left(1-x_{i}\right) l_{p}-u_{c}\right) Q_{i T t}+d_{1} n_{1}-d_{1} p_{1}=E P_{t} \\
& x_{i} \geq x_{\min } \\
& n \\
& \sum_{i=1}^{n} Q_{i T t}+d_{2} n_{2}-d_{2} p_{2}=E Q_{T t} \\
& Q_{i T t} \leq Q_{i \max } \\
& \lambda+n_{1}-p_{1} \leq 1 \\
& \lambda+n_{2}-p_{2} \leq 1 \\
& n_{1} \times p_{1}=0 \\
& n_{2} \times p_{2}=0 \\
& x_{i}, n_{j}, p_{j} \geq 0, i=1,2 \ldots, n \quad j=1,2
\end{aligned}
$$


The result of the fuzzy goal programming model gives us the fixed discount rate, the total sales amount goal and total profit goal of each vendor.

\subsubsection{Constructing mathematical model for DS2}

In this strategy the fuzzy goal programming model constructed for DS1 is used to determine the total profit goal and total sales amount goal of the vendors who prefer this strategy. Then quantity intervals which will have different discount rates and related probabilities $\left(p_{j}\right)$ of these quantity intervals for the vendor who prefers this strategy are determined by analyzing past data. After having the intervals managers determine the additional discount rate $(\beta)$ between the intervals. Following linear programming model is solved for each vendor:

$$
\begin{aligned}
& \min \sum_{j=1}^{n} k_{j} \\
& \sum_{j=1}^{n}\left(p_{j} \times Q_{T}\right)\left(\left(1-x_{j}\right) \times l_{p}-u_{c}\right)=E P_{t} \\
& x_{j+1}-x_{j}-e_{j}=\beta \\
& e_{j+1}-e_{j}=k_{j+1} \times e_{j+1} \\
& x_{j} \geq x_{\min } \\
& x_{j} \geq 1-\frac{(1+\alpha) C_{p}}{l_{p}} \\
& x_{j} \leq 0.1 R L_{i} \\
& x_{j} \leq 1-\frac{p_{\min } u_{c}-u_{c}}{l_{p}} \\
& x_{j}, e_{j} \geq 0, k_{j}=0,1
\end{aligned}
$$

\subsubsection{Constructing mathematical model for DS3}

Quantity intervals which will have different discount rates for the vendor who prefers this strategy are determined by expert opinions. Managers determine the additional discount rate $(\beta)$ which will be applied after achieving total sales amount of upper limit $\left(U L_{j}\right)$ of an interval. Following linear programming model is solved for each vendor using the results of fuzzy goal programming model constructed for DS1:

$$
\begin{aligned}
& \min \sum_{j=1}^{m} k_{j} \\
& \sum_{j=1}^{m}\left(U L_{j}-U L_{j-1}\right)\left(\left(1-x_{j}\right) \times l_{p}-u_{c}\right)=E P_{t} \\
& x_{j+1}-x_{j}-e_{j}=\beta \\
& e_{j+1}-e_{j}=k_{j+1} \times e_{j+1} \\
& x_{j} \geq x_{\min } \\
& x_{j} \geq 1-\frac{(1+\alpha) C_{p}}{l_{p}} \\
& x_{j} \leq 0.1 R L_{i} \\
& x_{j} \leq 1-\frac{p_{\min } u_{c}-u_{c}}{l_{p}} \\
& x_{j}, e_{j} \geq 0, k_{j}=0,1
\end{aligned}
$$




\subsubsection{Constructing mathematical model for DS4}

For discounting strategy 4 , the model used for DS 3 is modified. If the vendor prefers strategy 4 , the same fuzzy goal programming and linear programming models are used and the discount rate of the vendor is defined as $x_{1}$. The unit bonuses for each quantity is calculated by the equation given below:

$$
\left(\left(1-x_{1}\right) \times l_{p}-u_{c}\right)-\frac{1}{U L_{m}} \sum_{i=1}^{m}\left(U L_{i}-U L_{i-1}\right)\left(\left(1-x_{i}\right) \times l_{p}-u_{c}\right)=b_{m} .
$$

\section{A real world application}

A real case study is performed to validate the proposed model. An international company, which sales isolation materials for construction sector, is analyzed. The company works with more than 300 vendors which are located in 56 cities. The vendor sales performances in the presence of different discounting strategies are determined by using statistical analyses of the past data. The result of this analysis shows that the change in the discounting strategy has a significant effect on the sales volume of each vendor. Each vendor is affected from the different discounting strategies but the ways of this effect is changing from one to another.

To validate the proposed method a pilot city where 46 vendors are located in and a product which has one of the largest sales volumes are selected. When the past data are analyzed it is seen that 27 of the vendors are active (purchased in the last year) and 11 of them ordered more than 4 times and purchased at least 5000 units in last year. The total profit gained from these 11 vendors is more than $60 \%$ of total profit of the related product. Therefore the method is used for these 11 vendors.

Before constructing fuzzy goal programming model, vendors are analyzed to determine their risks. The parameters which are given in Section 1.3 are used to determine the risk level of each vendor. By using FAHP the weights of the criteria and sub-criteria are obtained as shown in Table 2.

The results of the FAHP shows that the most important main criteria which determines the risk level of a vendor is financial yield with a weight more than $50 \%$. Actually this is not an unexpected result because the financial yield is the main criteria which directly affects surviving of companies and the vendor which brings higher the financial yields will be more important and trustable for the company. As a result of this, profitability is the most important

Table 2. Criteria weights for risk level of a vendor

\begin{tabular}{ccccc}
\hline Main Criteria & $\begin{array}{c}\text { Main Criteria } \\
\text { Weights }\end{array}$ & Sub-Criteria & $\begin{array}{c}\text { Sub-Criteria } \\
\text { Weights }\end{array}$ & $\begin{array}{c}\text { Final Sub-Criteria } \\
\text { Weights }\end{array}$ \\
\hline$F Y$ & 0.5007 & $S R$ & 0.316 & 0.1582 \\
& & $P r$ & 0.684 & 0.3425 \\
& 0.2512 & $P D$ & 0.4626 & 0.1162 \\
& & ON & 0.4626 & 0.1162 \\
$F N$ & \multirow{2}{*}{0.2481} & Po & 0.0748 & 0.0188 \\
& & $F R$ & 0.3158 & 0.0783 \\
& & $R P$ & 0.6842 & 0.1697 \\
\hline
\end{tabular}


sub-criteria for the determination of riskiness of vendors. Also it is seen that potential of a vendor is the least important sub-criteria. This is because of that potential of a vendor is determined by the future expectations which are not certain.

The risk levels of the vendors are calculated and given in Table 3.

Table 3. Scores and risk levels of the vendors

\begin{tabular}{|c|c|c|c|c|c|c|c|c|c|c|c|c|c|c|c|}
\hline & & $\begin{array}{c}\text { SR } \\
W: 0.1582)\end{array}$ & & $\begin{array}{l}\text { PD } \\
: 0.1162)\end{array}$ & & $\begin{array}{l}\text { ON } \\
: 0.1162)\end{array}$ & & $\begin{array}{l}\text { Po } \\
\text { T:0.0188) }\end{array}$ & & $\begin{array}{c}\operatorname{Pr} \\
\text { J:0.3425) }\end{array}$ & & $\begin{array}{l}\text { FR } \\
\text { V:0.0783) }\end{array}$ & & $\begin{array}{l}\mathrm{RP} \\
\mathrm{v}: 0.1697)\end{array}$ & \\
\hline Code & $S$ & WS & S & WS & S & WS & S & WS & S & WS & S & WS & S & WS & RI \\
\hline 05 & & 0407 & 10 & 1.1620 & 10 & 1.1620 & 6 & & 5 & & 10 & 0.7830 & 10 & 1.6970 & 7.5785 \\
\hline 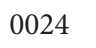 & 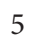 & ס & 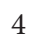 & & $J$ & & 8 & & 7 & & 10 & & 10 & & \\
\hline & 8 & $1.2 \mathrm{G}$ & 10 & & 10 & & 10 & & 7 & & 10 & & 10 & & \\
\hline & 6 & 0.9492 & 10 & & 10 & & 8 & & 6 & & 9 & & 8 & & \\
\hline & 6 & 0.9492 & 6 & 0.69 & 10 & & 8 & & 8 & 2.7400 & 8 & 0.62 & 2 & & \\
\hline 355 & 7 & 1074 & 8 & 0.9296 & 10 & & 8 & 0.1504 & 7 & 2.3975 & 7 & 0.5481 & 10 & 1.6970 & \\
\hline & 5 & 0.7910 & 4 & 0.4648 & 6 & 0.6972 & 6 & & 4 & 1.3700 & 10 & 0.7830 & 10 & & \\
\hline 1548 & 5 & 0.7910 & 4 & 0.4648 & 10 & 1.1620 & 8 & 0.1504 & 4 & 1.3700 & 9 & 0.7047 & 8 & 1.3576 & 6.0005 \\
\hline 1550 & 3 & 0.4746 & 4 & 0.4648 & 5 & 0.5810 & 6 & 0.1128 & 10 & 3.4250 & 10 & 0.7830 & 10 & 1.6970 & 7538 \\
\hline 1552 & 5 & 0.7910 & 0 & 0 & 0 & 0 & 8 & 0.1504 & 4 & 1.3700 & 10 & 0.7830 & 10 & 1.6970 & 4.7914 \\
\hline 1806 & 5 & 0.7910 & 0 & 0 & 0 & 0 & 6 & 0.1128 & 6 & 2.055 & 9 & 0.7047 & 10 & 1.6970 & 5.3605 \\
\hline
\end{tabular}

A questionnaire which is used to determine the preferred discounting strategy for each vendor is prepared. In the questionnaire 4 discounting strategies which are detailed in Section 1.1 are asked to be prioritized by vendors. In the last part of the questionnaire vendors determined the expected improvement ratio on their total sales volume when they get $1 \%$, $2 \%$ and $3 \%$ additional discounting.

The vendor sales performances in the presence of different discount rates are determined by using statistical analyses of the past data and the results of the questionnaire. The past data for the selected group of the vendors are given in Table 4 where the list price is $\$ 3.3$ and the unit cost is $\$ 1.2$.

Table 4. Past data of vendors at time period $t-1$

\begin{tabular}{cccccccc}
\hline & $i$ & $Q_{T i}$ & $R F_{i}$ & $x_{i}$ & Profit & $S_{i}$ & $Q_{\text {imax }}$ \\
\hline 0005 & 1 & 15,200 & 7.5785 & 0.36 & 16,781 & 0.026 & 20,000 \\
0024 & 2 & 12,000 & 6.8647 & 0.35 & 13,680 & 0.014 & 15,000 \\
0341 & 3 & 38,800 & 8.6551 & 0.42 & 34,454 & 0.022 & 50,000 \\
0345 & 4 & 26,440 & 7.5409 & 0.38 & 27,286 & 0.013 & 40,000 \\
0641 & 5 & 13,000 & 6.6646 & 0.40 & 12,480 & 0.012 & 25,000 \\
0855 & 6 & 22,000 & 7.9920 & 0.40 & 21,120 & 0.025 & 30,000 \\
1389 & 7 & 51,000 & 5.9158 & 0.42 & 45,288 & 0.012 & 60,000 \\
1548 & 8 & 15,760 & 6.0005 & 0.37 & 16,832 & 0.008 & 25,000 \\
1550 & 9 & 9,040 & 7.5382 & 0.39 & 9,004 & 0.006 & 12,000 \\
1552 & 10 & 15,640 & 4.7914 & 0.35 & 17,830 & 0.005 & 25,000 \\
1806 & 11 & 6,120 & 5.3605 & 0.36 & 6,756 & 0.018 & 10,000 \\
\hline
\end{tabular}


The managers are asked to define the desired goals for each objective. For the total sales volume, they want to achieve an improvement around $10 \%$ whereas this value is around $20 \%$ of the previous year's values for the total profit. It is acceptable for the profit goal to be $\$ 265000$ with $\$ 20000$ deviation and 247500 unit for the sales volume with a deviation of 10000 units. List price of the next year is determined as $\$ 3.6$ where the unit cost is $\$ 1.3$. The managers demand that there should be at least $20 \%$ profit per each sales transaction which makes the maximum discount rate $60 \%$. The closest competitor's price is $\$ 3.3$ and $\alpha$ is determined as 0.05. Fuzzy goal programming model for DS1 is constructed as follows:

$$
\begin{aligned}
& \max \lambda \\
& x_{i} \geq 1-\frac{(1.05) 3.3}{3.9} \\
& x_{i} \leq 0.1 \times R F_{i} \\
& x_{i} \geq 0.20 \\
& Q_{i T t}=Q_{i T(t-1)} \times\left(1+S_{i}\right)\left(\frac{\left(x_{i t}-x_{i(t-1)}\right)}{0.01}\right) \\
& \sum_{i=1}^{n}\left(\left(1-x_{i}\right) l_{p}-u_{c}\right) Q_{i T t}+20000 n_{1}-20000 p_{1}=265000 \\
& \sum_{i=1}^{n} Q_{i T t}+10000 n_{2}-10000 p_{2}=247500 \\
& Q_{i T t} \leq Q_{\max } \\
& \lambda+n_{1}-p_{1} \leq 1 \\
& \lambda+n_{2}-p_{2} \leq 1 \\
& n_{1} \times p_{1}=0 \\
& n_{2} \times p_{2}=0 \\
& x_{i}, n_{j}, p_{j} \geq 0, i=1,2 \ldots, n \quad j=1,2 \\
&
\end{aligned}
$$

Results of the fuzzy goal programming model which gives the discount rates for DS1 are given in Table 5.

Table 5. Discount rates for DS1 at time period $t$

\begin{tabular}{ccccc}
\hline Code & $i$ & $x_{i}$ & Expected Profit & Expected Amount \\
\hline 0005 & 1 & 0.4547 & 16,023 & 19,383 \\
0024 & 2 & 0.4119 & 12,995 & 13,078 \\
0341 & 3 & 0.5193 & 27,678 & 48,160 \\
0345 & 4 & 0.4332 & 25,781 & 28,323 \\
0641 & 5 & 0.3691 & 14,538 & 12,530 \\
0855 & 6 & 0.4795 & 19,541 & 26,773 \\
1389 & 7 & 0.3549 & 57,372 & 47,192 \\
1548 & 8 & 0.20 & 25,049 & 13,763 \\
1550 & 9 & 0.20 & 14,685 & 8,069 \\
1552 & 10 & 0.20 & 26,413 & 14,513 \\
1806 & 11 & 0.3216 & 7,690 & 5,715 \\
\hline
\end{tabular}


The discount rates which are given in Table 5 results in $\$ 247,765.7$ total profit and 237,500 units of total sales amount in year 2015. This means with the application of the proposed model company will have approximately $12 \%$ increase on total profit and $6 \%$ increase on total sales amount.

The results of the questionnaires show that most of the vendors prefer DS1. One of the selected 11 vendors prefers DS2 which has the code of 0345 . For the vendor 0345 an adjustment on the discount rates is made which yields same total sales volume and same total profit for the vendor. Total expected quantity of Vendor 0345 is 28,323 and total expected profit is $\$ 25,781$ as seen in Table 5. For Vendor 0345 managers decided to give 0.03 difference between the discount rates of each interval and the intervals are determined as shown in Table 6. In that table, the probability of being in the related interval for an ordering amount which is calculated using past data and the expected amounts of the intervals which are calculated by multiplying the probability with the expected total sales amount are also given.

Table 6. Expected total sales amounts of the intervals

\begin{tabular}{cccc}
\hline$j$ & Quantity & Probability $\left(p_{j}\right)$ & Expected Amount \\
\hline 1 & $<1199$ & 0.2 & $5,664.6$ \\
2 & $1200-1779$ & 0.6 & $16,993.8$ \\
3 & $1800-2399$ & 0.15 & $4,248.45$ \\
4 & $>2400$ & 0.05 & $1,416.15$ \\
\hline
\end{tabular}

Linear programming model of DS2 for Vendor 0345 is constructed as follows:

$$
\begin{aligned}
& \min \sum_{j=1}^{n} k_{j} \\
& \sum_{j=1}^{n}\left(p_{j} \times Q_{T}\right)\left(\left(1-x_{j}\right) \times 3.9-1.3\right)=25781 \\
& x_{j+1}-x_{j}-e_{j}=0.03 \\
& e_{j+1}-e_{j}=k_{j+1} \times e_{j+1} \\
& x_{j} \geq 0.20 \\
& x_{j} \geq 0.1115 \\
& x_{j} \leq 0.75409 \\
& x_{j} \leq 0.60 \\
& x_{j}, e_{j} \geq 0, k_{j}=0,1
\end{aligned}
$$

The discount rates of each interval which are gained from the results of the linear programming model and the profits which are calculated for each interval for vendor 0345 are given in Table 7. 
Table 7. Probabilities of the intervals and final discount rates of vendor 0345 for DS2.

\begin{tabular}{lccccc}
\hline$j$ & Quantity & Probability & Expected Amount & Discount Rate & Profit \\
\hline 1 & $<1199$ & 0.2 & $5,664.6$ & 0.401769328 & 5,852 \\
2 & $1200-1779$ & 0.6 & $16,993.8$ & 0.431769328 & 15,568 \\
3 & $1800-2399$ & 0.15 & $4,248.45$ & 0.461769328 & 3,395 \\
4 & $>2400$ & 0.05 & $1,416.15$ & 0.491769328 & 966 \\
Total & & & 28,323 & & 25,781 \\
\hline
\end{tabular}

Questionnaires show that Vendors 0341 prefers DS3. For Vendor 0341, it is decided that the discount rates will be changed in multiples of 10,000 units, and the difference of the discount rates between each level is determined as 0.05 . Linear programming model for Vendor 0341 is constructed as follows:

$$
\begin{aligned}
& \min \sum_{j=1}^{m} k_{j} \\
& \sum_{j=1}^{m}\left(U L_{j}-U L_{j-1}\right)\left(\left(1-x_{j}\right) \times 3.9-1.3\right)=27678 \\
& x_{j+1}-x_{j}-e_{j}=0.05 \\
& e_{j+1}-e_{j}=k_{j+1} \times e_{j+1} \\
& x_{j} \geq 0.20 \\
& x_{j} \geq 0.1115 \\
& x_{j} \leq 0.8655 \\
& x_{j}, e_{j} \geq 0, k_{j}=0,1
\end{aligned}
$$

Final discount rates of vendor 0345 for DS3 are given in Table 8.

Table 8. Upper levels of the intervals and final discount rates of vendor 0341 for DS3

\begin{tabular}{cccc}
\hline$j$ & $U L_{j}$ & Discount Rate & Cumulative Profit \\
\hline 0 & 0 & - & - \\
1 & 10,000 & 0.42784359 & $9,314.1$ \\
2 & 20,000 & 0.47784359 & $16,678.2$ \\
3 & 30,000 & 0.52784359 & $22,092.3$ \\
4 & 40,000 & 0.57784359 & $25,556.4$ \\
5 & 48,160 & 0.6 & 27,678 \\
\hline
\end{tabular}

It is seen that none of the 11 vendors prefers DS4, but to illustrate the proposed model we calculate the unit bonuses which will be paid to the vendor if the vendor 0345 prefers DS4. The discount rate of the vendor 0345 is defined as $x_{1}$ which is 0.4278 . The unit bonuses for each quantity level are calculated by the equation given below and shown in Table 9:

$$
((1-0.4278) \times 3.9-1.3)-\frac{1}{U L_{m}} \sum_{i=1}^{m}\left(U L_{i}-U L_{i-1}\right)\left(\left(1-x_{i}\right) \times 3.9-1.3\right)=b_{m} \text {. }
$$


Table 9. Unit bonuses of vendor 0345 for DS4

\begin{tabular}{ccc}
\hline$i$ & Sales Amount & Unit Bonus \\
\hline 0 & 0 & - \\
1 & 20,000 & 0.0975 \\
2 & 30,000 & 0.1950 \\
3 & 40,000 & 0.2925 \\
4 & 48,160 & 0.3566 \\
\hline
\end{tabular}

With application of the proposed method, the company decided the discount rates for each vendor considering their expectations and by this way company achieved to increase both its total profits and market share simultaneously.

In addition, the application of the proposed method shows that the additional discount rates for DS2 and DS3, which is the core factor directs the vendor to a relatively safer discounting strategy for the manufacturer, should be determined attentively.

\section{Conclusions}

The proposed methodology, which aims to determine the discounting strategies and discount rates for vendors based on their expectations, become prominent in such a way that managers enhance increase on the total sales amount and the total profit, enabling sales representatives negotiate with the vendors on the discounting strategy and motivating vendors by fulfilling their expectations regarding discounting strategy. In the methodology, the risk level of each vendor is determined which could be used to develop appropriate strategies for risky vendors and provides an opportunity to the managers to be on the safe side. For example, if a vendor is at a small risk level value which means it is a risky vendor, the payment conditions could be revised to make sure that the payment would be received or the sales representatives could prompt the vendor to choose a discounting strategy that involves a commitment. One of the most important advantages of the proposed method is increasing vendor loyalty. It is seen that vendors who have an opportunity to choose a discounting strategy from several options make more efforts to increase the sales amount and have better discount rate options in the following years. Therefore, we believe that application of the proposed method will result in incremental market share along with incremental total profits for companies.

For further researches, it is suggested to extend this method by using intelligent techniques on the determination process of vendor behaviors with respect to the additional discount rates and improve its accuracy. Since it is one of the significant parameters on the proposed method, decreasing the uncertainty on this relation will increase the achievement rate of the goals. Additionally, the model could be extended in a way that determines the discount rates for all the vendors including new ones by determining new discounting strategies. 


\section{References}

Aissaoui, N.; Haouari, M.; Hassini, E. 2007. Supplier selection and order lot sizing modeling: a review, Computers and Operations Research Research 34(12): 3516-3540.

https://doi.org/10.1016/j.cor.2006.01.016

Braide, S.; Cao, Z.; Zeng, X. 2012. Volume discount pricing strategy in the VMI supply chain with price sensitive demand, Journal of the Operational Research Society 64(6): 833-847. https://doi.org/10.1057/jors.2012.85

Buckley, J. J. 1985. Fuzzy hierarchical analysis, Fuzzy sets and systems 17(3): 233-247. https://doi.org/10.1016/0165-0114(85)90090-9

Cheng, Y. 2013. Research on dynamic pricing based on rationing for two deterministic demand classes, Chapter 45, in W. Du (Ed.). Lecture notes in electrical engineering 207 LNEE. London: Springer-Verlag. https://doi.org/10.1007/978-1-4471-4793-0_45

Chung, J.; Li, D. 2013. The prospective impact of a multi-period pricing strategy on consumer perceptions for perishable foods, British Food Journal 115(3):377-393. https://doi.org/10.1108/00070701311314200

Croes, R. R.; Semrad, K. J.; Yost, E. 2010. Explaining the pricing decision-making process in the hotel industry, Chapter 4 in P. M. Berge, S. B. Eliassen (Eds). Hospitality and Tourism Management. New York: Nova Science Publishers.

Ertuğrul, İ.; Karakaşoğlu, N. 2009. Performance evaluation of Turkish cement firms with fuzzy analytic hierarchy process and TOPSIS methods, Expert Systems with Applications 36(1): 702-715. https://doi.org/10.1016/j.eswa.2007.10.014

Galankashi, M. R.; Chegeni, A.; Soleimanynanadegany, A.; Memari, A.; Anjomshoae, A.; Helmi, S. A.; Dargi, A. 2015. Prioritizing green supplier selection criteria using fuzzy analytical network process, Procedia CIRP 26: 689-694. https://doi.org/10.1016/j.procir.2014.07.044

Hannan, E. L. 1981. Linear programming with multiple fuzzy goals, Fuzzy Sets and Systems 6: 235-248. https://doi.org/10.1016/0165-0114(81)90002-6

Haq, A. N.; Kannan, G. 2006. Fuzzy analytical hierarchy process for evaluating and selecting a vendor in a supply chain model, The International Journal of Advanced Manufacturing Technology 29(7-8): 826-835.

Harries, C.; Yaniv, I.; Harvey, N. 2004. Combining advice: the weight of a dissenting opinion in the consensus, Journal of Behavioral Decision Making 17(5): 333-348. https://doi.org/10.1002/bdm.474

Hsieh, C.-C.; Liu, Y.-T.; Wang, W.-M. 2010. Coordinating ordering and pricing decisions in a two-stage distribution system with price-sensitive demand through short-term discounting, European Journal of Operational Research 207(1): 142-151. https://doi.org/10.1016/j.ejor.2010.03.035

Hsieh, T. Y.; Lu, S. T.; Tzeng, G. H. 2004. Fuzzy MCDM approach for planning and design tenders selection in public office buildings, International Journal of Project Management 22(7): 573-584.

https://doi.org/10.1016/j.ijproman.2004.01.002

Jakhar, S. K. 2015. Performance evaluation and a flow allocation decision model for a sustainable supply chain of an apparel industry, Journal of Cleaner Production 87: 391-413. https://doi.org/10.1016/j.jclepro.2014.09.089

Kahraman, C.; Cebeci, U.; Ulukan, Z. 2003. Multi-criteria supplier selection using fuzzy AHP, Logistics Information Management 16(6): 382-394. https://doi.org/10.1108/09576050310503367

Kamali, A.; Ghomi, S. F.; Jolai, F. 2011. A multi-objective quantity discount and joint optimization model for coordination of a single-buyer multi-vendor supply chain, Computers and Mathematics with Applications 62(8): 3251-3269. https://doi.org/10.1016/j.camwa.2011.08.040

Kar, A. K. 2014. Revisiting the supplier selection problem: an integrated approach for group decision support, Expert Systems with Applications 41(6): 2762-2771. https://doi.org/10.1016/j.eswa.2013.10.009

Kilincci, O.; Onal, S. A. 2011. Fuzzy AHP approach for supplier selection in a washing machine company, Expert Systems with Applications 38(8): 9656-9664. https://doi.org/10.1016/j.eswa.2011.01.159 
Kumar, A. 2016. A conceptual model for automation of product dynamic pricing and sales promotion for a retail organization, Kybernetes 45(3): 490-507. https://doi.org/10.1108/K-03-2015-0075

Kumar, M.; Vrat, P.; Shankar, R. 2004. A fuzzy goal programming approach for vendor selection problem in a supply chain, Computers and Industrial Engineering 46(1): 69-85.

https://doi.org/10.1016/j.cie.2003.09.010

Senvar, M. O.; Vayvay, O.; Kurt, E.; Hloch, S. 2014. Prioritization of balanced scorecard measurement indicators as a process management approach via fuzzy AHP: case study in automotive industry, Tehnicki Vjesnik 21(1): 155-162.

Shaw, K.; Shankar, R.; Yadav, S. S.; Thakur, L. S. 2012. Supplier selection using fuzzy AHP and fuzzy multi-objective linear programming for developing low carbon supply chain, Expert Systems with Applications 39(9): 8182-8192. https://doi.org/10.1016/j.eswa.2012.01.149

Sinha, S.; Sarmah, S. P. 2010a. Single-vendor multi-buyer discount pricing model: an evolutionary computation-based approach, International Journal of Operational Research 8(1): 1-19. https://doi.org/10.1504/IJOR.2010.033101

Sinha, S.; Sarmah, S. P. 2010b. Single-vendor multi-buyer discount pricing model under stochastic demand environment, Computers \& Industrial Engineering 59(4): 945-953. https://doi.org/10.1016/j.cie.2010.09.005

Tam, M. C.; Tummala, V. R. 2001. An application of the AHP in vendor selection of a telecommunications system, Omega 29(2): 171-182. https://doi.org/10.1016/S0305-0483(00)00039-6

Van Laarhoven, P. J. M.; Pedrycz, W. 1983. A fuzzy extension of Saaty's priority theory, Fuzzy Sets and Systems 11(1): 199-227. https://doi.org/10.1016/s0165-0114(83)80082-7

Viswanathan, S.; Wang, Q. 2003. Discount pricing decisions in distribution channels with price-sensitive demand, European Journal of Operational Research 149(3): 571-587. https://doi.org/10.1016/S0377-2217(02)00469-1

Wadhwa, V.; Ravindran, A. R. 2007. Vendor selection in outsourcing, Computers and Operations Research 34(12): 3725-3737. https://doi.org/10.1016/j.cor.2006.01.009

Wang, T. Y.; Yang, Y. H. 2009. A fuzzy model for supplier selection in quantity discount environments, Expert Systems with Applications 36(10): 12179-12187. https://doi.org/10.1016/j.eswa.2009.03.018

Wang, Z.; Hu, M. 2014. Committed versus contingent pricing under competition, Production and Operations Management 23(11): 1919-1936. https://doi.org/10.1111/poms.12202

Weber, C. A.; Current, J. R.; Benton, W. C. 1991. Vendor selection criteria and methods, European Journal of Operational Research 50(1): 2-18. https://doi.org/10.1016/0377-2217(91)90033-R

Yahya, S.; Kingsman, B. 1999. Vendor rating for an entrepreneur development programme: a case study using the analytic hierarchy process method, Journal of the Operational Research Society 50(9): 916-930. https://doi.org/10.1057/palgrave.jors.2600797

Yang, J. L.; Chiu, H. N.; Tzeng, G. H.; Yeh, R. H. 2008. Vendor selection by integrated fuzzy MCDM techniques with independent and interdependent relationships, Information Sciences 178(21): 4166-4183. https://doi.org/10.1016/j.ins.2008.06.003

Yin, M.; Kim, K. H. 2012. Quantity discount pricing for container transportation services by shipping lines, Computers and Industrial Engineering 63(1):313-322. https://doi.org/10.1016/j.cie.2012.03.008

Zeng, J.; An, M.; Smith, N. J. 2007. Application of a fuzzy based decision making methodology to construction project risk assessment, International Journal of Project Management 25(6): 589-600. https://doi.org/10.1016/j.ijproman.2007.02.006

Irem UCAL SARI. PhD, Department of Industrial Engineering. Istanbul Technical University. First degree in environmental engineering, Istanbul Technical University (2004). Master of Science in engineering management (2008). PhD in industrial engineering (2012). Research interests: engineering economics, multiple criteria decision making, fuzzy sets applications to decision making and revenue management. 